OPEN ACCESS

Edited by:

Anna Esposito,

University of Campania 'Luigi

Vanvitelli, Italy

Reviewed by:

Hui Jing Lu,

Hong Kong Polytechnic University,

Hong Kong

Dejan Jakimovski,

Buffalo Neuroimaging Analysis

Center, United States

${ }^{*}$ Correspondence:

X.T. Wang

xtwang@cuhk.edu.cn

Specialty section

This article was submitted to

Human-Media Interaction,

a section of the journal

Frontiers in Psychology

Received: 04 November 2020

Accepted: 04 June 2021

Published: 08 July 2021

Citation:

Li H and Wang X (2021)

Cyber-Personality and Liking

Expression: A Study From WeChat

Users in China.

Front. Psychol. 12:626040.

doi: 10.3389/fpsyg.2021.626040

\section{Cyber-Personality and Liking Expression: A Study From WeChat Users in China}

\author{
Haojian Li and X.T. Wang* \\ School of Humanities and Social Science, The Chinese University of Hong Kong, Shenzhen, China
}

Clicking the like button following a post on social media has become a common means of expressing and gathering social support online. Little is known about how liking expression is linked and regulated by personality traits and communication motives. Following a preliminary survey $(n=168)$ about the usage of the like function on WeChat, a Chinese social media platform, we conducted an online study $(n=183)$ to map the Big-Five personality traits and five communication motives to the frequency (likelihood) of liking expression. The results showed that each user had, on average, 385 WeChat friends and spent 2.2 hours and used the liking function 1.1 times each day on WeChat. The personality trait conscientiousness was negatively related to the liking expression ( $\beta=-0.505, p<0.05)$. In contrast, agreeableness promoted the expression of liking directly $(\beta=0.153, p<0.05)$ and indirectly via two communication motives, enjoyment (a: $\beta=0.377, p<0.01$; b: $\beta=0.433, p<0.001$ ) and passing time (c: $\beta=0.578, p<$ 0.05 ; $\mathrm{d}: \beta=0.523, p<0.001)$. The liking expression may serve as a simple index for understanding dispositional underpinnings of social media networking.

Keywords: cyberpersonality, communication motives, social media, WeChat, liking expression, personality traits

\section{INTRODUCTION}

\section{Cyber-Personality and Motives of Online Communication}

Cyber-personality, human personality in cyberspace, has emerged as a new topic in social and personality psychology. The researchers have suggested that people's online behaviors, including online communication and online self-expression, are regulated by some specific personality traits and motivational factors (e.g., Anolli et al., 2005; Orchard and Fullwood, 2010; Attrill, 2015). In contrast to the vast amount of research on behavioral effects of personality in real life, little is known about how different personality traits manifest in the cyber-environment. The manifestations of personality traits and social motives in the cyber-environment may or may not be consistent with their behavioral effects observed in the actual world. The knowledge about personality effects in actual environments cannot be simply applied to cyber environments. For instance, a timid person in the real world may be highly aggressive in the cyber world. As the first step of the investigation, we intend to focus on a common and measurable online behavior and map it to specific personality traits as traditionally measured by the Big-Five personality inventory. In addition, we also map the online behavior to motivation constructs that drive and regulate social networking.

The online behavior examined in this research is the action of clicking the like button following a WeChat post, including, visual, auditory, or text message. WeChat is the most popular social media platform in China with over 1.2 billion monthly active users worldwide as of the first quarter of 2020, according to Statista.com. WeChat plays a dominant role in China's social media and influences people's online behavior, it enhances trust and personal 
contacts while transforming opportunities for larger online group formation (Harwit, 2017). WeChat users join friend circles, called "moments" which is similar to a Twitter post. The like function is one of the most common tools of expressing and gathering social support on WeChat. For this study, we chose this behavior because it is used readily by all the WeChat users to express social support. Secondly, the like clicking behavior is equally tractable and quantifiable for all its users.

In this research, we first establish a behavioral profile of liking behavior followed by a second study to analyze the relationship between the liking behavior and personality (i.e., the Big-Five personality traits) and motives underlying social networking (i.e., enjoyment seeking, pleasing others, and interpersonal relationship formation). Thus, the like expression may be used as a fast and frugal index of unique personality and social motive profiles. In addition, we examined which factors, dispositional or situational, are more significant regulators of the like expression behavior in social media.

\section{The Like Function in Communication on Social Media}

The like function of WeChat provides a ready means for the users to selectively show individualized social support at their fingertips. Compared to comment on a post, which is a cognitively triggered behavior, like expression is more affectively driven (Kim and Yang, 2017). In general, the use of the like button reflects users' enjoyment of, agreement with, or interest in a specific post (Basalingappa et al., 2016). People within a social media group are not only liking others but also care about receiving likes from others. For the senders, likes signal social acceptance and maintain interpersonal relationships. For the receivers, the likes catch their attention with low cognitive load and have become a new source of social reward (Scissors et al., 2016). For adolescents, likes are considered a sign of social approval (Martinez-Pecino and Garcia-Gavilán, 2019). In particular, adolescents with little social support show a significant preference for these kinds of online social interactions (Leung, 2011). In general, likes serve as a cue of status and popularity (Blease, 2015). However, the overuse of social media may result in distress by increasing communication overload and reducing self-esteem (Chen and Lee, 2013).

Previous studies have primarily focused on the joint use of liking, commenting, and sharing and their communicational functions, based on data from Facebook, Twitter, or Instagram (Guo and Sun, 2020; Luo et al., 2020; Obamiro et al., 2020). The present study focuses on the link between the like expressions on WeChat and users' basic personality traits and communication motives. First, in a preliminary survey, we glean the behavioral profile of WeChat use in general and liking expression in particular. We then map personality traits and communication motives to the frequency of like expression.

\section{Personality Traits and Communication Motives and Liking Expression}

To map the like behavior onto basic personality traits and communication motives of the WeChat users, we chose the widely-accepted Big-Five personality traits (Goldberg, 1992; John and Srivastava, 1999) as our personality measures. In usergenerated online use of social media, users' personality traits play a crucial role in their engagement in and selection of social media.

Extraversion and openness to experience have been found to increase online activities and engagement in social media (Ross et al., 2009; Correa et al., 2010). However, other studies found that some extroverts may use social media for social enhancement and some introverts may use social media to compensate for the lack of social interactions in face-to-face contexts (Zywica and Danowski, 2008). For neuroticism, some researchers believe that a high level of neuroticism had a greater impact on messaging use and online texting. Neurotic individuals reported stronger addictive tendencies in mobile phone use (Ehrenberg et al., 2008). However, other studies showed that neuroticism was unrelated to online activities and engagement in social media (Ross et al., 2009). For agreeableness, it was reported that a low score was associated with low involvement in social media (Landers and Lounsbury, 2006) and a higher intention for maintaining existing relationships (Horzum, 2016).

Regarding motivations of the consumers of social media, the literature suggests two major motives, enjoyment seeking and interpersonal relationship maintenance, derived from an influential theory in the field of communication, uses and gratifications theory (Rubin, 1994; Ruggiero, 2000; Quan-Haase and Young, 2010; Whiting and Williams, 2013). The theory explains how people use social media to gratify their needs. According to the theory, users select different media based on their motivational needs. In a more recent study, Lee et al. (2016) identified from the literature five types of motives that make the users click the like button on Facebook. Of the five communication motives (i.e., enjoyment, pleasing others, monetary incentive, pass time, and interpersonal relationship), enjoyment, and interpersonal relationship are the two most salient motives. A cross-cultural study with Chinese users on WeChat (Gan and Wang, 2015) also confirmed that the two major types of gratifications, besides finding content information, were hedonic and social gratifications. In the present study, we focused on the aforementioned five communication motives because they are unique for social media use and also overlap with basic human needs (Maslow, 1954).

Quan-Haase and Young (2010) reported that Facebook use is associated more with having fun and knowing about the social activities occurring in one's social network, whereas instant messaging is geared more toward relationship maintenance and development. For this study, we examine not only what type of need the like function on WeChat fulfill but also how motives and personality traits separately or jointly affect the users to click the like button on WeChat.

Our research questions derived from the aforementioned discussion are as follows:

RQ1. How do people use the like function on WeChat?

RQ2. Is there any particular personality trait that regulates the use of like expression?

RQ3. What communication motives are driving the use of the like function? 
Although we do not have strong predictions regarding the aforementioned research questions, we hypothesize that the use of the like function on WeChat will be affected by the user's personality and communication movies. In particular, two of the Big-Five personality traits, agreeableness and conscientiousness would likely affect the use of liking expressions. While agreeableness may increase the use of the like function (e.g., Landers and Lounsbury, 2006), conscientiousness may reduce the use of the like function due to a more cautious and responsible attitude. In addition, we predict that the effects of agreeableness on the use of the like function would be mediated by communication motives, particularly, the enjoyment-seeking motive, as suggested by some previous findings (Lee et al., 2016).

\section{MATERIALS AND METHODS}

\section{Participants}

In this research, two samples were collected from university students in Beijing. We conducted a preliminary survey to learn how the young participants use WeChat and the like function ( $n=168,50$ male participants). For the main study, the sample consisted of 190 volunteer participants who use WeChat daily. Seven participants failed to complete the survey and were excluded from data analysis. The age of the main sample $(n=$ 183) ranged from 17 to 23 years, with an average age of 18.3 \pm 0.91 years. This research was endorsed by the IRB of the university and conducted before the outbreak of the COVID19 pandemic.

\section{Measures}

\section{Preliminary Survey Questionnaire}

The questions in the survey gathered basic information about the usage of WeChat and the like function, including the number of friends on WeChat, the time spent each day on WeChat, the frequency of using the like function, the percentages of the WeChat posts that the participants agree, trust, and considered useful, etc. (for more details see Appendix).

\section{Big-Five Personality Scale}

In the main study, we measured the Big-Five personality traits using the 60 items of the NEO-FFI inventory (Costa and McCrae, 1992). The inventory assesses five personality traits: extraversion, agreeableness, conscientiousness, emotional stability, and openness to experience. The Chinese version of this inventory had been used and tested previously (Yao and Liang, 2010). Participants responded to the items on a 5-point Likert scale ( $1=$ strongly disagree to $7=$ strongly agree). The Cronbach's alpha coefficients in the present study were 0.86 for extroversion, 0.83 for conscientiousness, 0.70 for agreeableness, 0.66 for openness, and 0.81 for neuroticism (emotional stability).

\section{Communication Motives for Using the Like Function}

We adopted a 21-item inventory developed by Lee et al. (2016) to measure how the like expression on WeChat is related to the following five communication motives: enjoyment, pleasing others, monetary incentive, passing time, and interpersonal relationship. The questionnaire begins with an incomplete statement "I click like on WeChat because ..." followed with 21 items, such as "I enjoy the content," "It helps me fit in with a group of people," "It helps me receive a bargain deal," "It helps me pass time when I am bored.", and "It helps me improve relations with friends." The participants rated these statements on a 7 -point scale with 1 meaning strongly disagree and 7 meaning strongly agree. In this scale, the Cronbach's $\alpha$ is 0.79 for enjoyment, 0.87 for pleasing others, 0.93 for money incentive, 0.82 for passing time, 0.91 for interpersonal relationship.

\section{Dependent Variable}

The dependent variable was a frequency rating of like expression on WeChat. The participants were asked: "How frequently do you use the like function on WeChat?" The response was measured on a Likert-type scale with the following response anchors: $1=$ never, $2=$ rarely, $3=$ occasionally, $4=$ sometimes, $5=$ often, $6=$ usually, $7=$ always (Vagias, 2006). We chose this Liker-type response instead of an absolute estimation such as the number of like clicking each day which is likely to vary from time to time and be subjective to memory biases. The current measure is a numerical likelihood estimate in comparison to other WeChat users.

\section{Procedure and Data Analysis}

We first conducted a preliminary survey to obtain a WeChat user profile. In the following main study, the questionnaires were distributed online. The consent for participation was obtained before answering the questions. The personality and motivation measures were presented in a balanced order.

Descriptive statistics, Pearson's correlations with BenjaminiHochberg correction, were calculated. We then conducted a hierarchical regression analysis to reveal the unique contributions of each set of factors (i.e., Big-Five personalities, communication motives) to the model, followed by a pathanalysis to sort out the relationships between Big-Five personality traits, communication motives, and liking expression on WeChat.

\section{RESULTS}

\section{The Results From the Preliminary Survey}

To answer RQ1, the preliminary survey gathered basic information to obtain a WeChat user profile. We also asked the participants for their basic attitude toward, perception of, and emotional experience with the like function on WeChat (see Appendix).

In general, the frequency of using like is much higher than using some other functions (e.g., retweet, comment, and create a new post). The frequency of liking behavior was positively correlated with other endorsement behaviors such as retweets. The use of the like function was considered a means of expressing immediate positive feedback.

Each user had, on average, $385.4 \pm 322.5$ friends on WeChat and spent $2.21 \pm 1.19 \mathrm{hrs}$ and used the liking function $1.1 \pm$ 0.52 times each day on WeChat. Of the posts consumed by the participants, $62 \%$ were considered trustworthy, $57 \%$ were agreeable, and $44 \%$ were considered meaningful. The participants 
TABLE 1 | Means, standard deviations, intercorrelations between sex, age, personality traits, communication motives, and liking expression, and $P$-values with Benjamini-Hochberg correction.

\begin{tabular}{|c|c|c|c|c|c|c|c|c|c|c|c|c|c|c|}
\hline & & 1 & 2 & 3 & 4 & 5 & 6 & 7 & 8 & 9 & 10 & 11 & 12 & 13 \\
\hline 1 & Gender & 1 & & & & & & & & & & & & \\
\hline 2 & Age & 0.04 & 1 & & & & & & & & & & & \\
\hline 3 & Openess & -0.08 & -0.05 & 1 & & & & & & & & & & \\
\hline 4 & Agreeableness & 0.05 & -0.06 & -0.02 & 1 & & & & & & & & & \\
\hline 5 & Conscientiousness & -0.04 & -0.10 & 0.02 & $0.30^{\star \star}$ & 1 & & & & & & & & \\
\hline 6 & Extroversion & 0.03 & $-0.15^{\star \star}$ & -0.05 & $0.46^{\star \star}$ & $0.47^{\star \star}$ & 1 & & & & & & & \\
\hline 7 & Neuroticism & 0.07 & 0.03 & 0.03 & $-0.41^{\star \star}$ & $-0.38^{\star \star}$ & $-0.56^{\star \star}$ & 1 & & & & & & \\
\hline 8 & Enjoyment & $-0.19^{\star \star}$ & -0.08 & 0.00 & $0.20^{\star \star}$ & 0.05 & 0.13 & -0.01 & 1 & & & & & \\
\hline 9 & Pleasing others & 0.03 & -0.06 & -0.09 & $0.16^{*}$ & $-0.15^{\star}$ & 0.06 & -0.10 & $0.31^{\star \star}$ & 1 & & & & \\
\hline 10 & Money incentive & 0.06 & -0.05 & $-0.19^{\star \star}$ & 0.13 & -0.02 & 0.02 & -0.10 & $0.19^{\star \star}$ & $0.49^{\star \star}$ & 1 & & & \\
\hline 11 & Passing time & -0.11 & 0.01 & $-0.15^{\star}$ & $0.16^{*}$ & -0.1 & 0.08 & 0.02 & $0.15^{\star}$ & $0.38^{\star \star}$ & $0.21^{\star \star}$ & 1 & & \\
\hline 12 & Interpersonal Relation & -0.11 & -0.10 & -0.08 & $0.18^{*}$ & -0.07 & 0.001 & 0.02 & $0.49^{\star \star}$ & $0.64^{\star \star}$ & $0.30^{\star \star}$ & $0.38^{\star *}$ & 1 & \\
\hline \multirow[t]{2}{*}{13} & Liking Expression & -0.14 & -0.02 & -0.08 & $0.21^{\star *}$ & $-0.15^{\star}$ & 0.06 & 0.02 & $0.29^{\star *}$ & $0.34^{\star \star}$ & $0.16^{\star}$ & $0.54^{\star \star}$ & $0.35^{\star \star}$ & 1 \\
\hline & $p$-values ${ }^{\S}$ & ns & ns & ns & 0.015 & ns & ns & ns & 0.00036 & 0.00001 & ns & 0.00001 & 0.00001 & \\
\hline Mean & & 1.72 & 18.84 & 3.38 & 3.397 & 3.43 & 3.3 & 2.98 & 5.30 & 3.25 & 3.18 & 3.57 & 4.43 & 4.02 \\
\hline SD & & 0.45 & 0.91 & 0.42 & 0.444 & 0.57 & 0.64 & 0.61 & 0.83 & 1.23 & 1.75 & 1.66 & 1.33 & 1.84 \\
\hline
\end{tabular}

$N=183$

${ }^{*} p<0.05 ;{ }^{* \star} p<0.01$.

$\S_{p}$-values with Benjamini-Hochberg correction.

ns, not significant.

would use the like function only when they liked or strongly liked a post. The frequency rating exceeded the middle point on the response scale (see Appendix).

These results suggest that WeChat users did not abuse the like function which is easy to use at their fingertips. The rate of reposting a message was even lower, which was about once every 3 days.

\section{Regression Analysis of Personality Traits, Motives, and the Like Expressions}

Table 1 shows the means, standard deviations, and intercorrelations between the Big-Five personality traits, five communication motives, and the frequency rating of like expression on WeChat. To control the family-wide type-1 error, we conducted Benjamini-Hochberg correction to the predictors of Like expression (see p-values with Benjamini-Hochberg correction in Table 1). The frequency rating of like expression was positively correlated with the personality trait agreeableness and all five communication motives. and negatively correlated with the personality trait conscientiousness (not significant after Benjamini-Hochberg correction).

To test our hypothesis regarding RQ2 and RQ3 and to further sort out the relative contributions of the personality and motivational factors on like expression, we conducted hierarchical regression analysis.

Table 2 shows the results of hierarchical regression analysis with the frequency rating of liking expression as the dependent variable. We conducted a hierarchical regression analysis to reveal the unique contributions of each set of factors (i.e., Big Five personalities, communication motives) to the model. We chose hierarchical regression to allow hypothesis-based placement of variables into the model instead of automated and algorithmbased analysis, such as stepwise regression. Gender and age were entered in the first step, followed by adding the personality traits at the second step, and the five communication motives in the third step. Communication motives were placed into the hierarchical regression following the personality measures based on the consideration that the motives of communication are more domain-specific than the Big-Five personality traits and are expected to mediate the effects of personalities.

Concerning the liking expression, age and gender only accounted for $2 \%$ of the variance in the dependent variable. No sex-personality trait interaction or sex-communication motive interaction effects were detected.

The predictability of the model improved significantly by adding the personality traits, which accounted for a further $14.2 \%$ of the variance. The motivation traits accounted for another $37.8 \%$ of the variance. The total percentage of the variance accounted for by the full model reached $54 \%$. In Table 2 , we reported $R^{2}$ and Adjusted $R^{2}$ for model fitting and tested multicollinearity using the variance inflation factor (VIF). The VIF scores (far right column) were all lower than 2, indicating that the predictors included in the multiple regression were not highly correlated with each other.

\section{Direct and Indirect Effects of Personality Traits and Communication Motives on the Liking Expression}

To further test our hypothesis about mediation effects of motivation between personality and the use of the like function, we conducted path analyses using M-plus and revealed 
TABLE 2 | Hierarchical regression results of the contributions of age and gender (first step), personality traits (second step), and communication motives (third step) to liking expression on WeChat.

Model

Unstandardized coefficients

$\beta$

\section{Liking expression on WeChat}

2

3

Age

Gender

Age

Gender

Age

Neuroticism

Extroversion

Conscientiousness

Agreeableness

Openness

Gender

Age

Neuroticism

Extroversion

Conscientiousness

Agreeableness

Openness

Pleasing others

Money incentive

Passing time

Interpersonal relation

Enjoyment

$R^{2}$ step 1

$R^{2}$ step 2

$R^{2}$ step 3

$R^{2}$ total
$-0.566$

$-0.026$

$-0.743$

$-0.023$

0.359

0.3

$-0.806$

1.231

$-0.384$

$-0.331$

$-0.011$

0.133

0.041

$-0.456$

0.669

$-0.078$

0.156

$-0.033$

0.477

0.001

0.341

0.02

0.142

0.378

0.54
Standardized coefficients

$\beta$

VIF

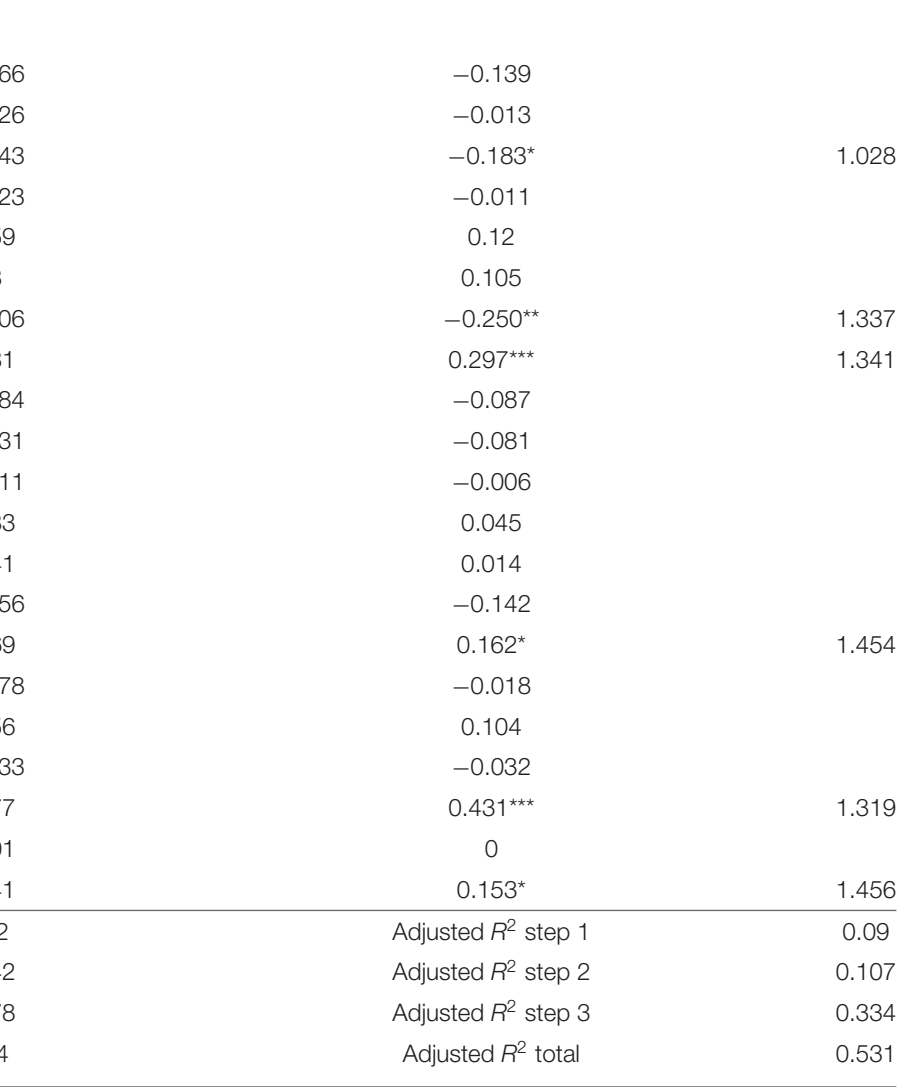

$N=183$

${ }^{*} p<0.05 ;{ }^{* *} p<0.01 ;{ }^{* * *} p<0.001$.

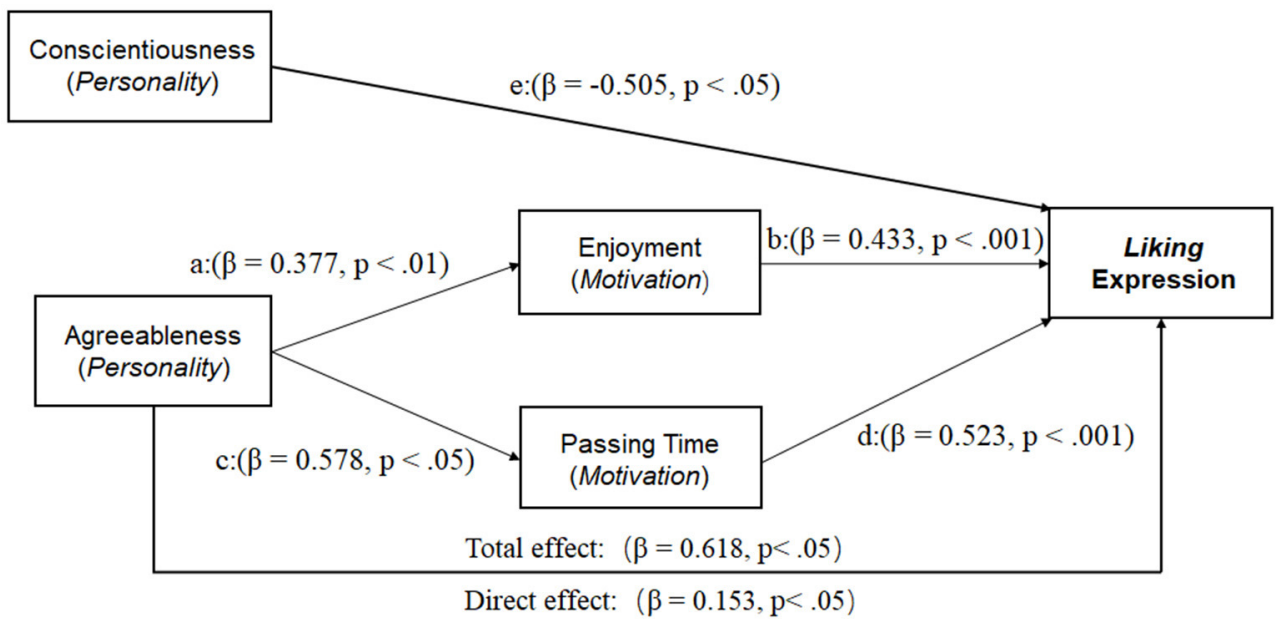

FIGURE 1 | Relationship between personality, motivation, and liking expression. 
direct and indirect effects of personality and motivation on liking expressions.

As shown in Figure 1, the personality trait conscientiousness was negatively related to the liking expression $(\beta=-0.505$, $p<0.05$ ), suggesting that higher conscientiousness makes a public expression of social support more serious and less casual. In contrast, another Big-Five personality trait agreeableness promoted the expression of liking directly (e: $\beta=0.153$, $p<0.05)$ and indirectly via two communication motives, enjoyment, and passing time. First, the participants who had higher conscientiousness perceived themselves to be less likely to use the liking expression. This direct effect suggests that agreeableness lowers the threshold for a person to express social support in a cyber-environment.

Second, the positive effects of agreeableness on the liking expression were mediated by two communication motives. One of the mediating motives was the enjoyment motive, with a path from agreeableness to enjoyment motive (a: $\beta=0.377$, $p<0.01)$ and then from the enjoyment motive to the liking expression (b: $\beta=0.433, p<0.001$ ). A bias-corrected bootstraps confidence interval for the indirect effect $(\mathrm{ab}=0.163)$ based on 5,000 bootstrap samples was entirely above zero (0.012-0.315). This mediation effect suggests that using the liking function on social media was a pleasant experience and self-rewarding.

The second mediating factor was the motive of passing time, with a link from agreeableness to the motive (c: $\beta=0.578, p<$ 0.05 ) and a final link from the motive to the liking expression (d: $\beta=0.523, p<0.001$ ). This indirect pathway shows that the liking expression on social media provides a way of killing time. A bias-corrected bootstraps confidence interval for the indirect effect $(\mathrm{cd}=0.302)$ based on 5,000 bootstrap samples was entirely above zero (0.012-0.592).

The effect of agreeableness on like expression was reduced after controlling the two motives but remained statically significant (see the outer path in Figure 1, $p<0.05$ ). Therefore, the result indicates a partial mediation effect between agreeableness and the liking expression via the two communication motives. Moreover, the mediating effects of the two motives were especially stronger for a personality of higher agreeableness and lower conscientiousness. The whole model with two partial mediating pathways and one direct pathway had a significant fit of data $\left(R^{2}=0.337, p<0.001\right)$.

\section{GENERAL DISCUSSION}

We derived from the data a four-factor model of dispositional effects on the liking expression in communication on social media (see Figure 1). Consistent with our hypothesis, the personality traits agreeableness and conscientiousness had, respectively, positive and negative effects on like expression. Moreover, the hypothesis that the communication motives mediate the effects of personality traits on the liking expression is partially supported where only a single trait (agreeableness) was mediated by leisure-related communication motives.

What the liking function is not about should be also important to learn. Liking expressions are neither associated with introversion-extraversion nor emotional stability nor openness to experience. In the present study, the sores of extraversion were not significantly correlated with the use of the like function on WeChat. The subjective frequency estimate of like expression did not distinguish introverts from extroverts. Both introverts and extroverts may benefit from using the like function for different reasons. Introverts may benefit from the like function to build up their social relations without face-to-face interactions while extroverts may use the liking expression for social enhancement (Zywica and Danowski, 2008).

The use of the liking function on social media is neither for simply pleasing others nor for utilitarian purposes. In a follow-up study, we asked a group of student participants about the time they spent and the number of the like expressions they used each day on WeChat during the COVID19 pandemic. The results showed that both measures were not statistically different before and after this environmental change. Thus, the use of the liking function on social media was not easily susceptible to situational changes in one's environment, indicating it is more of an index of dispositional than situational factors.

Overall, our results indicate that the liking expression is more dispositional than situational. It is regulated by personality traits and communication motives rather than situational factors (e.g., environmental changes, health risks, and presumably emotional state due to the COVID-19 pandemic). The findings of the present study suggest that people did not abuse the easy function of liking expression on social media. Instead, expressing such social support is regulated by conscientiousness and agreeableness, and mediated by communication motives of passing time and enjoyment seeking.

\section{Limitations and Future Directions}

This research has its limitations in its design. First, a clear limitation of this study is its limited demographic sample with little age variation. Our sample was homogeneous, including mainly young university students. These participants are likely to be more active in cyberspace, whose communication motives may be different from other user groups. Second, our measure of the use of the like function was a likelihood estimate in comparison to other users in one's friend circle.

People use the like function on WeChat for both lighthearted topics and more serious topics. It is plausible and can be examined in future studies that agreeableness is associated more with light-hearted topics while conscientiousness is associated more with serious topics.

Future studies should adopt multiple measures, including the actual frequency measure, attitude toward using the like function, and self-confidence measures of social media networking. A comprehensive measure of liking expressions may yield a more reliable and valid index for the cyber-personality profiling of the users of social media. 


\section{CONCLUSION}

The current study is the first to build the user profile of liking expressions on WeChat and to link the liking expression to its underlying personality traits and communication motives. The results showed that the liking expression is only linked with limited personality traits (conscientiousness and agreeableness) and communication motives (passing time and enjoyment seeking) and is more sensitive to these dispositional factors than situational factors, such as changes due to the COVID-19 pandemic. The unique user profile associated with the liking expression makes it a simple and readily available tool for predicting particular communication needs and personal characteristics of social media consumers. The frequency of liking expressions reveals the dispositional underpinnings of individual users and social media groups.

\section{DATA AVAILABILITY STATEMENT}

The raw data supporting the conclusions of this article will be made available by the authors, without undue reservation.

\section{REFERENCES}

Anolli, L., Villani, D., and Riva, G. (2005). Personality of people using chat: an on-line research. Cyberpsychol. Behav. 8, 89-95. doi: 10.1089/cpb.2005.8.89

Attrill, A. (2015). Cyberpsychology. Oxford: Oxford University Press.

Basalingappa, A., Subhas, M. S., and Tapariya, R. (2016). Understanding likes on Facebook: an exploratory study. Online J. Commun. Media Technol. 6:234. doi: $10.29333 / \mathrm{ojcmt} / 2566$

Blease, C. R. (2015). Too many 'friends', too few 'likes'? Evolutionary psychology and 'Facebook depression.' Rev. Gen. Psychol. 19, 1-13. doi: $10.1037 /$ gpr0000030

Chen, W., and Lee, K.-H. (2013). Sharing, liking, commenting, and distressed? The pathway between Facebook interaction and psychological distress. Cyberpsychol. Behav. Soc. Netw. 16, 728-734. doi: 10.1089/cyber.2012.0272

Correa, T., Hinsley, A. W., and Zúñiga, H. G. D. (2010). Who interacts on the Web?: the intersection of users' personality and social media use. Comput. Human Behav. 26, 247-253. doi: 10.1016/j.chb.2009.09.003

Costa, P. T., and McCrae, R. R. (1992). Revised NEO Personality Inventory (NEOPIR) and NEO Five Factor Inventory (NEO-FFI) Professional Manual. Odessa, FL: Psychological Assessment Resources.

Ehrenberg, A., Juckes, S., White, K. M., and Walsh, S. P. (2008). Personality and self-esteem as predictors of young people's technology use. CyberPsychol. Behav. 11, 739-741. doi: 10.1089/cpb.2008.0030

Gan, C., and Wang, W. (2015). Uses and gratifications of social media: a comparison of microblog and WeChat. J. Syst. Inform. Technol. 17, 351-363. doi: 10.1108/JSIT-06-2015-0052

Goldberg, L. R. (1992). The development of markers for the Big-Five factor structure. Psychol. Assess. 4, 26-42. doi: 10.1037/1040-3590.4.1.26

Guo, M., and Sun, F. S. (2020). Like, comment, or share? Exploring the effects of local television news Facebook posts on news engagement. J. Broadcast. Electron. Media 64, 736-755. doi: 10.1080/08838151.2020.1851125

Harwit, E. (2017). WeChat: social and political development of China's dominant messaging app. Chin. J. Commun. 10, 312-327. doi: 10.1080/17544750.2016.1213757

Horzum, M. B. (2016). Examining the relationship to gender and personality on the purpose of Facebook usage of Turkish university students. Comput. Human Behav. 64, 319-328. doi: 10.1016/j.chb.2016.06.010

\section{ETHICS STATEMENT}

The studies involving human participants were reviewed and approved by the Ethics Committee of the School of Humanities and Social Science, Chinese University of Hong Kong, Shenzhen. The participants provided their informed consent to participate in the study.

\section{AUTHOR CONTRIBUTIONS}

HL: methodology, investigation, data curation and analysis, and writing- original draft preparation. XW: conceptualization, methodology, validation, resources, data analysis, writingreviewing and editing, project supervision, and funding acquisition. All authors contributed to the article and approved the submitted version.

\section{FUNDING}

This work was supported, in part, by the National Natural Science Foundation of China under Grant Number NSFC 31971025 to XW.

John, O. P., and Srivastava, S. (1999). The Big Five trait taxonomy: history, measurement, and theoretical perspectives. Handbook Person. Theory Res. 2, 102-138.

Kim, C., and Yang, S. U. (2017). Like, comment, and share on Facebook: how each behavior differs from the other. Public Relat. Rev. 43, 441-449. doi: 10.1016/j.pubrev.2017.02.006

Landers, R. N., and Lounsbury, J. W. (2006). An investigation of Big Five and narrow personality traits in relation to Internet usage. Comput. Human Behav. 22, 283-293. doi: 10.1016/j.chb.2004.06.001

Lee, S.-Y., Hansen, S. S., and Lee, J. K. (2016). What makes us click "like" on Facebook? Examining psychological, technological, and motivational factors on virtual endorsement. Comput. Commun. 73, 332-341. doi: 10.1016/j.comcom.2015.08.002

Leung, L. (2011). Loneliness, social support, and preference for online social interaction: the mediating effects of identity experimentation online among children and adolescents, Chin. J. Commun. 4, 381-399. doi: 10.1080/17544750.2011.616285

Luo, T., Freeman, C., and Stefaniak, J. (2020). "Like, comment, and share"-professional development through social media in higher education: a systematic review. Educ. Technol. Res. Dev. 68, 1659-1683. doi: 10.1007/s11423-020-09790-5

Martinez-Pecino, R., and Garcia-Gavilán, M. (2019). Likes and problematic Instagram use: the moderating role of self-esteem. Cyberpsychol. Behav. Soc. Netw. 22, 412-416. doi: 10.1089/cyber.2018.0701

Maslow, A. H. (1954). Motivation and Personality. New York, NY: Harper

Obamiro, K., West, S., and Lee, S. (2020). Like, comment, tag, share: Facebook interactions in health research. Int. J. Med. Inform. 137:104097. doi: 10.1016/j.ijmedinf.2020.104097

Orchard, L. J., and Fullwood, C. (2010). Current perspectives on personality and internet use. Soc. Sci. Comput. Rev. 28, 155-169. doi: 10.1177/0894439309335115

Quan-Haase, A., and Young, A. L. (2010). Uses and gratifications of social media: a comparison of Facebook and instant messaging. Bull. Sci. Technol. Soc. 30, 350-361. doi: 10.1177/0270467610380009

Ross, C., Orr, E. S., Sisic, M., Arseneault, J. M., Simmering, M. G., and Orr, R. R. (2009). Personality and motivations associated with Facebook use. Comput. Human Behav. 25, 578-586. doi: 10.1016/j.chb.2008.12.024 
Rubin, A. M. (1994). "Media uses and effects: a uses-and-gratifications perspective," in LEA's Communication Series. Media Effects: Advances in Theory and Research, eds J. Bryant and D. Zillmann (New Jersey: Lawrence Erlbaum Associates), 417-436.

Ruggiero, T. E. (2000). Uses and gratifications theory in the 21st century. Mass Commun. Soc. 3, 3-37. doi: 10.1207/S15327825MCS0301_02

Scissors, L., Burke, M., and Wengrovitz, S. (2016). "What's in a Like? Attitudes and behaviors around receiving Likes on Facebook," in Proceedings of the 19th ACM Conference on Computer-Supported Cooperative Work and Social Computing CSCW'16 (New York; NY). doi: 10.1145/2818048.2820066

Vagias, W. M. (2006). Likert-type scale response anchors. Clemson International Institute for Tourism and Research Development, Department of Parks, Recreation and Tourism Management, Clemson University.

Whiting, A., and Williams, D. (2013). Why people use social media: a uses and gratifications approach. Qual. Mark. Res. 16, 362-369. doi: 10.1108/QMR-06-2013-0041

Yao, R., and Liang, L. (2010). Analysis of the application of simplified NEO-FFI to undergraduates. Chin. J. Clin. Psychol. 18, 457-459.
Zywica, J., and Danowski, J. (2008). The faces of Facebookers: investigating social enhancement and social compensation hypotheses; predicting Facebook ${ }^{\mathrm{TM}}$ and offline popularity from sociability and self-esteem, and mapping the meanings of popularity with semantic networks. $J$. Comput. Mediat. Commun. 14, 1-34. doi: 10.1111/j.1083-6101.2008. 01429.x

Conflict of Interest: The authors declare that the research was conducted in the absence of any commercial or financial relationships that could be construed as a potential conflict of interest.

Copyright (C) 2021 Li and Wang. This is an open-access article distributed under the terms of the Creative Commons Attribution License (CC BY). The use, distribution or reproduction in other forums is permitted, provided the original author(s) and the copyright owner(s) are credited and that the original publication in this journal is cited, in accordance with accepted academic practice. No use, distribution or reproduction is permitted which does not comply with these terms. 


\section{APPENDIX}

TABLE A1 | A user profile of Liking expressions on WeChat $(n=168)$ with descriptive statistics of frequency estimates, likelihood $(1=$ rare, $2=$ unlikely, $3=$ possible, 4 $=$ likely, 5 = almost certain) and agreement ( $1=$ agree and $5=$ disagree) ratings on a 5-point scale.

\begin{tabular}{|c|c|c|c|c|}
\hline & Minimum & Maximum & Mean & SD \\
\hline 1. How long in hours do you use WeChat each day? & 1 & 5 & 2.2 & 1.2 \\
\hline 2. How many WeChat friends do you have? & 30 & 3,000 & 385.0 & 322.5 \\
\hline 3. How many like expressions do you send to other's posts (e.g., text, video, image, article) every 3 days? & 1 & 8 & 3.3 & 1.6 \\
\hline 4.1. Out of every 10 posts you read on WeChat, how many of them do you agree with? & 2.0 & 9.0 & 5.7 & 1.3 \\
\hline 4.2. Out of every 10 posts you read on WeChat, how many of them do you think are meaningful? & 1.0 & 9.0 & 4.4 & 1.7 \\
\hline 4.3. Out of every 10 posts you read on WeChat, how many of them do you trust? & 1.0 & 9.0 & 6.2 & 1.6 \\
\hline 4.4. Out of every 10 posts you read on WeChat, how many of them do you feel passionate about? & 1.0 & 8.0 & 4.5 & 1.6 \\
\hline 5.1. How likely are you to click the like button to endorse a post you somewhat like? & 1.0 & 5.0 & 2.9 & 0.9 \\
\hline 5.2. How likely are you to click the like button to endorse a post you like? & 1.0 & 5.0 & 3.3 & 0.9 \\
\hline 5.3. How likely are you to click the like button to endorse a post you strongly like? & 1.0 & 5.0 & 4.0 & 1.0 \\
\hline 6.1. How likely are you to click the like button to endorse a post you somewhat dislike? & 1.0 & 5.0 & 2.1 & 0.9 \\
\hline 6.2. How likely are you to click the like button to endorse a post you dislike? & 1.0 & 5.0 & 2.3 & 1.1 \\
\hline 6.3. How likely are you to click the like button to endorse a post you strongly dislike? & 1.0 & 5.0 & 2.8 & 1.3 \\
\hline 7.1. When you agree with a post, how likely are you to click the like button? & 1.0 & 5.0 & 4.1 & 0.8 \\
\hline 7.2. When you agree with a post, how likely are you to make a comment? & 1.0 & 5.0 & 3.3 & 1.0 \\
\hline 7.3. When you agree with a post, how likely are you to retweet the post to other WeChat friends? & 1.0 & 5.0 & 2.7 & 1.1 \\
\hline 7.4. When you agree with a post, how likely are you to just keep it to yourself? & 1.0 & 5.0 & 3.2 & 1.0 \\
\hline 8.1. When you disagree with a post, how likely are you to click the like button? & 1.0 & 4.0 & 1.7 & 0.8 \\
\hline 8.2. When you disagree with a post, how likely are you to make a comment? & 1.0 & 4.0 & 2.2 & 1.1 \\
\hline 8.3. When you disagree with a post, how likely are you to retweet the post to other WeChat friends? & 1.0 & 4.0 & 1.8 & 0.9 \\
\hline 8.4. When you disagree with a post, how likely are you to just keep it to yourself? & 1.0 & 5.0 & 3.8 & 1.1 \\
\hline 8.5. When you disagree with a post, how likely are you to block the author of the post? & 1.0 & 5.0 & 2.5 & 1.2 \\
\hline 9. Do you think WeChat should add a Dislike button? & 1 & 5 & 2.3 & 1.1 \\
\hline
\end{tabular}

